Int. J. Electrochem. Sci., 11 (2016) $6609-6626$

\title{
Evaluation of Inhibition Efficiency of 1-(2-pyridylazo) -2- naphthol and Bromide Ion on the Corrosion of Mild Steel in Sulphuric Acid Solution
}

\author{
Lin Wang ${ }^{1, *}$, Hao Zheng ${ }^{1}$, Xue-Min $\mathrm{Zi}^{2}$, Shi-Wen Zhang ${ }^{1}$, Li Peng ${ }^{1}$, Jie Xiong ${ }^{1}$ \\ ${ }^{1}$ School of Chemical Science and Technology, Key Laboratory of Medicinal Chemistry for Nature \\ Resource, Ministry of Education, Yunnan University, Kunming, Yunnan, 650091, P. R. China \\ ${ }^{2}$ Yunnan Three Circles-Sinochem Fertilizers Co. Ltd, Kunming, Yunnan, 650114, P. R. China \\ *E-mail: wanglin@ynu.edu.cn, wanglin2812@163.com
}

doi: $10.20964 / 2016.08 .17$

Received: 11 April 2016 / Accepted: 25 May 2016 / Published: 7 July 2016

\begin{abstract}
The corrosion inhibition of mild steel in $0.5 \mathrm{~mol} / \mathrm{L}$ sulphuric acid solution by bromide ion in the absence and presence of 1-(2-pyridylazo)-2-naphthol (PAN) has been studied by potentiodynamic polarization, electrochemical impedance spectroscopy and weight loss. Potentiodynamic polarization researches show that single bromide ion or the complex of bromide ion and PAN acts as a mixed-type inhibitor and do not change the mechanism of either hydrogen evolution reaction or metal dissolution. The charge transfer process controls the corrosion reaction. The studies reveal that the complex of bromide ion and PAN shows a quite well inhibition and their synergistic effect was observed and discussed. The adsorption of the inhibitors on the steel surface obeys the Langmuir adsorption isotherm. The thermodynamic parameters such as adsorptive equilibrium constant $\left(K_{\text {ads }}\right)$, adsorption free energy $\left(\Delta G^{\mathrm{o}}\right.$ ads $)$, adsorption heat $\left(\Delta H^{\mathrm{o}}{ }_{a d s}\right)$ and adsorption entropy $\left(\Delta S^{\mathrm{o}}{ }_{a d s}\right)$, kinetic data such as apparent activation energy $\left(E_{\mathrm{a}}\right)$ and pre-exponential factor $(A)$ were calculated and discussed. The values of $\Delta G^{\mathrm{o}}$ ads indicate that the adsorption of the inhibitors on the mild steel surface in $0.5 \mathrm{~mol} / \mathrm{L}$ $\mathrm{H}_{2} \mathrm{SO}_{4}$ solution is a mixed physical and chemical adsorption mechanism and the chemical adsorption is the dominant in the presence of bromide ion and PAN together.
\end{abstract}

Keywords: Corrosion inhibition, Mild steel, Electrochemical techniques, Adsorption, Thermodynamic properties, Synergistic effect, Sulphuric acid.

\section{FULLTEXT}

(C) 2016 The Authors. Published by ESG (www.electrochemsci.org). This article is an open access article distributed under the terms and conditions of the Creative Commons Attribution license (http://creativecommons.org/licenses/by/4.0/). 